assessment. Hearing screening or audiometry is also included within the Extracorporeal Life Support Organization (ELSO) recommendations for the care of children post-ECMO.

Methods A retrospective survey was sent to families of children who were supported on ECMO run between 2008 and 2017 in a large paediatric ECMO centre. The aim of this questionnaire was to enquire about their experiences, follow up and any hearing or neuro-developmental difficulties their children had experienced. Families were also asked if their children had undergone hearing screening after hospital discharge. The central and local notes (if available) of these children were reviewed to look for evidence of audiological assessment.

Results 146 surveys were sent out with 64 families responding representing a $43.8 \%$ return rate. Thirty four of the families who responded (53\%) report their children had hearing screening after ECMO. Seven families (11\%) expressed concern about their children's hearing. There was evidence of hearing screening in the medical notes of only $28 \%$ responders (18 children). Most of these were not planned assessments due to the history of ECMO. The children undergoing hearing screening were referred due to concerns such as speech delay and recurrent ear infections. Forty four percent of children (8/18) had documented hearing screening because of their previous ECMO run.

Conclusions Over half of children who have had an ECMO run were reported by their parents to have had hearing screening completed though there was only documentation of the results in $28 \%$ of those where it was said to be undertaken. In the cases of documented audiological assessment, $56 \%$ of these were due to concerns raised out with routine post-ECMO assessment. It is important to raise awareness of the hearing screening requirement in children after ECMO and look at implementing a robust system to ensure this takes place. The responsibility for ensuring this takes place should lie with the ECMO centre.

\section{G216(P) TO REVIEW THE DEMOGRAPHICS AND POSSIBLE REASONS BEHIND RECURRENT PAEDIATRIC ATTENDANCES TO A TERTIARY LEVEL EMERGENCY DEPARTMENT IN 2017}

JTB Baker, RC Clay. Emergency Department, Addenbrooke's Hospital, Cambridge, UK

\subsection{6/archdischild-2020-rcpch. 184}

Methods Utilising data for paediatric attendances to the Emergency Department in 2017, we applied certain selection criteria to our data. We excluded anyone sixteen years or older and anyone who reattended less than five times. We then recorded the age of the patient, sex of the patient, total number of attendances the patient had made, postcode and GP practice of the patient and also the likely diagnosis of each individual presentation.

Results In 2017, there were a total of 21,646 paediatric attendances to the Emergency Department. Of these, there were a total of 84 patients reattending with primary care issues.

Out of the total 21,646 attendances, 12,074 (55.8\%) were male and 9,572 (44.2\%) were female. Of the recurrent attenders this number was $43(51.2 \%)$ male and 41 (48.8\%) female.

The most common age for patients reattending was oneyear-old; this group made up a total of $26.2 \%$ of those

\begin{tabular}{ll} 
Abstract G216(P) Table 1 & \\
\hline Diagnosis & Total \\
\hline Viral URTI & 61 \\
Head Injury & 22 \\
Abdominal Pain & 17 \\
Bronchiolitis & 15 \\
Croup & 14 \\
Chest Infection & 14 \\
Viral gastroenteritis & 12 \\
Tonsillitis & 12 \\
Rash & 11 \\
Pulled elbow & 7 \\
Leg injury & 6 \\
Foot Injury & 6 \\
Viral illness & 6 \\
Viral-induced wheeze & 6 \\
Dehydration & 5 \\
Worried well & 5 \\
Fever & 5 \\
\hline
\end{tabular}

reattending. Other significant age groups were the two-yearolds who made up a total of $21.4 \%$ of those reattending and the three-year-olds who made up a total of $16.7 \%$ of those reattending.

Viral upper respiratory tract infections are by far the most common cause for reattendance in the population we studied - accounting for sixty-one total presentations. Head injuries accounted for twenty-two attendances and abdominal pain accounted for seventeen attendances. Other causes for reattendance can be seen in the table 1 below.

Conclusion Most patients who reattended the Emergency Department were young, generally being less than four-yearsold.

Viral respiratory tract infections and minor injuries are the most common causes for recurrent attendances. There are clearly many factors that need to be considered in patients reattending the Emergency Department; however, education of parents, particularly focusing on viral illnesses and minor injuries, remains an important step at trying to reduce recurrent Emergency Department attendances.

\section{G217(P) IMPROVING PAEDIATRIC ASTHMA LONG-TERM MANAGEMENT THROUGH THE EMERGENCY DEPARTMENT}

E Dyer, K Viljoen, A Iordanidou, C Sidira, M Butler. Paediatric Emergency Department, Evelina London Children's Hospital, London, UK

\subsection{6/archdischild-2020-rcpch.185}

Aims The UK has one of the worst paediatric asthma mortality rates in Europe. The National Review of Asthma Deaths found that we could prevent many deaths with better basic asthma care and long-term management. We aimed to improve the assessment of children with asthma in the Emergency Department (ED), and their long-term management.

Methods We collected data over three months on those $>5$ presenting to ED with asthma. We subsequently introduced an ED assessment proforma for these children. We re-audited 
over the same time period the following year and we have made changes to the proforma based on these results, which we will continue to re-assess, and further improve.

Results Between 2017 and 2018 we saw a 60\% increase in numbers of children attending ED with asthma. We were initially poor at recording patient/carer smoking status with this being done in $23 \%$ of patients. Following proforma introduction, this increased to $51 \%$. The objective assessment of chronic severity of asthma also improved, from 67\% having this documented in 2017 to $99 \%$ in 2018. However, we remained poor at documenting assessment of inhaler technique, recording this in only $23 \%$ of patients in 2017 and 13\% in 2018. Documentation of follow up plans was also poor and did not improve with proforma introduction. We also saw significant changes in practice; new preventer therapies were introduced in $2 \%$ of patients in 2017 , but $14 \%$ in 2018.

Conclusion We found that by designing a proforma with specific prompts we could affect what questions people asked, long-term management and documentation. This worked well for prompts we included such as smoking status and objective assessment of severity, though it did not work for other key points. We have now re-designed the proforma which is rolling out alongside education sessions. This includes a revised discharge checklist highlighting key care standards. We have included information to signpost parents/carers to smoking cessation services and flowcharts to ensure correct follow up is arranged. We have attempted to shift the approach of clinicians from treating just an exacerbation, to thinking about treating asthma as a chronic condition.

\section{G218(P) A NEW SEPSIS TOOL: IMPROVING THE MANAGEMENT OF CHILDREN WITH SUSPECTED SEPSIS IN OUR EMERGENCY DEPARTMENT, WITH AN UNEXPECTED BONUS}

${ }^{1} \mathrm{R}$ Clubb, ${ }^{2} \mathrm{~A}$ Dakova, ${ }^{2} \mathrm{~A}$ Anpananthar. ${ }^{1}$ Royal London Hospital, Barts Health NHS Trust, London, UK; ${ }^{2}$ Whipps Cross Hospital, Barts Health NHS Trust, London, UK

\subsection{6/archdischild-2020-rcpch. 186}

Aim Sepsis is a leading cause of morbidity and mortality in children. Early recognition and appropriate management can save lives.

With on-going staff cover challenges in our busy District General Hospital we wanted to implement sustainable changes to improve early recognition and prompt senior review and delivery of antibiotics to potentially septic children in the Emergency Department.

Method Following focus groups with key stakeholders and the multidisciplinary team (MDT), a sepsis triage tool based on the Wessex Paediatric Sepsis Tool was introduced to enable nurses to screen all children presenting with 'illnesses'. Retrospective analysis of ED data was performed before and after implementation. Three mini PDSA cycles helped us improve the tool, increase the MDT's engagement and make its continued use sustainable.

Results Focus groups suggested that the ED team found the tool easy to use and that it resulted in early review of children identified as potentially septic. Promptly amending the tool in response to feedback anecdotally helped keep staff engaged.
The pre-implementation audit undertaken in January 2019 screened 368 children who presented to the ED with an illness. Post-implementation, 300 children were screened. The time from arrival to a senior being notified of a potentially septic child who met the criteria for triggering the tool improved from 53 minutes to 19 minutes, while the time to senior review decreased to 2 hours 17 minutes, from 4 hours 29 minutes. Senior review of potentially septic children increased from $50 \%$ to $85 \%$.

Conclusion We achieved improvements in key times in the patient's journey, which could lead to improvement in patient flow in paediatric ED and reduced time to antibiotics. Implementation of this tool also encouraged regular education sessions on sepsis for the MDT.

Importantly, staff feedback though PDSA cycles has also opened other doors. It led to the conversion of two ED cubicles into paediatric critical care bays to facilitate rapid senior review, shorten the time taken to give antibiotics and improve patient flow in ED for other critically unwell children.

\section{G219(P) SOCIAL DEPRIVATION AND UPPER RESPIRATORY TRACT INFECTION IN THE NORTH EAST}

${ }^{1} \mathrm{C}$ Renouf, ${ }^{2} \mathrm{~A}$ Battersby, ${ }^{2} \mathrm{E}$ Lim, ${ }^{3,4} \mathrm{M}$ Emonts, ${ }^{4} \mathrm{M}$ Parker, ${ }^{3} \mathrm{H}$ Moll. ${ }^{1}$ Newcastle University, Newcastle upon Tyne, UK; ${ }^{2}$ General Paediatrics, Great North Children's Hospital, Newcastle upon Tyne, UK; ${ }^{3}$ Institute of Cellular Medicine, Newcastle University, Newcastle upon Tyne, UK; ${ }^{4}$ Paediatric Immunology, Infectious Diseases and Allergy, Great North Children's Hospital, Newcastle upon Tyne, UK

\subsection{6/archdischild-2020-rcpch. 187}

Aims This project aimed to identify a relationship between social deprivation and patients presenting to Paediatric A\&E with upper respiratory tract infection (URTI) in [region]. It also aimed to analyse the geographic spread of URTI patients presenting to Paediatric A\&E in the North East.

Methods This was a retrospective study using data from the European MOFICHE and PERFORM study databases. The postcodes of patients presenting to Great North Children's Hospital Paediatric A\&E with a working diagnosis of URTI $(n=1685)$ between April 2017 and March 2018 allowed classification of patients into Index of Multiple Deprivation (IMD) deciles using the English indices of deprivation 2015 tool. Individual patient postcodes were colour-coded by deprivation decile and pinned onto a visual map using the My Maps tool on Google Maps.

Results 58.4\% of URTI patients in Paediatric A\&E came from the most deprived households (IMD deciles 1 - 3), 15.7\% from the least deprived households (IMD deciles $8-10$ ) and $25.9 \%$ from households in between (IMD deciles $4-7$ ). Whilst there was a general trend of decreasing patient presentation with decreasing levels of deprivation, there was a slight increase in patients in IMD deciles 9 and 10 (see table 1).

\begin{tabular}{|c|c|c|c|c|c|c|c|c|c|c|}
\hline $\begin{array}{l}\text { Patient IMD } \\
\text { Deciles }\end{array}$ & 1 & 2 & 3 & 4 & 5 & 6 & 7 & 8 & 9 & 10 \\
\hline $\begin{array}{l}\text { Percent of } \\
\text { URTI Patients } \\
\text { in A\&E (\%) }\end{array}$ & 32.5 & 14.7 & 11.2 & 10.0 & 6.7 & 5.5 & 3.8 & 3.6 & 4.8 & 7.3 \\
\hline
\end{tabular}

